\title{
HORIZONTALIDADE SOCIAL TRANS: O DIREITO SOCIAL À SAÚDE DOS TRANSEXUAIS NAS RELAÇÕES ENTRE PARTICULARES
}

\author{
Luiz Geraldo do Carmo Gomes* \\ Jairo Néia Lima**
}

SUMÁRIO: Introdução; 2 Identidade de Gênero e Transexualidade; 3 Eficácia dos Direitos Sociais nas Relações Entre Particulares; 4 Considerações Finais; Referências.

RESUMO: O trabalho analisa o direito social à saúde em relação à população transexual e sua efetividade nas relações privadas. Os principais pontos discutidos na presente pesquisa dizem respeito à transexualidade como identidade de gênero; à teoria da eficácia horizontal dos direitos fundamentais; e à eficácia horizontal dos direitos sociais, especificamente. A partir de uma pesquisa bibliográfica dedutiva,demonstrou-se que a esfera privada não é imune à normatividade presente dos direitos fundamentais e, por isso, podem ter eficácia nas relações em que o poder estatal não está presente. Além disso, concluiu-se que o direito social à saúde do transexual merece, por meio de atendimento médico que leve em conta suas peculiaridades de corpo e mente, ser reconhecido na esfera privada.

PALAVRAS-CHAVE: Direito à Saúde; Eficácia Horizontal; Transexualidade; Eficácia Horizontal.

\section{TRANS SOCIAL HORIZONTALITY: THE SOCIAL RIGHT TO HEALTH OF TRANSSEXUAL PEOPLE IN THEIR RELATIONSHIPS WITH OTHERS}

ABSTRACT: Current paper analyzes the social right to health of transsexual populations and its efficaciousness in private relationships. The main points comprise transsexuality as gender identity, the theory of horizontal efficaciousness of fundamental rights, the horizontal efficaciousness of social rights. Research on deductive bibliography has revealed that the private sphere is not immune to norms inherent to fundamental rights and, consequently, they may be efficacious in relation-

\footnotetext{
"Doutor em Função Social do Direito (FADISP). Visiting Lecturer e Researcher na School of Law da University of Limerick (Irlanda). E-mail: lgcarmo@gmail.com

** Doutor em Direito Constitucional (USP). Docente do Programa de Mestrado e Doutorado em Ciência Jurídica da Universidade Estadual do Norte do Paraná (UENP). Brasil.
} 
ships where the State is not present. The transsexual person's social right to health should take into account the characteristics of body and mind, acknowledged within the private sphere.

KEY WORDS: Right to health; Horizontal efficacy; Transsexuality.

\section{HORIZONTALIDAD SOCIAL TRANS: EL DERECHO SOCIAL A LA SALUD DE LOS TRANSEXUALES EN LAS RELACIONES ENTRE PARTICULARES}

RESUMEN: El trabajo analiza el derecho social a la salud en relación a la población transexual y su efectividad en las relaciones privadas. Los principales puntos discutidos en la presente investigación se refieren a la transexualidad como identidad de género; a la teoría de la eficacia horizontal de los derechos fundamentales; y la eficacia horizontal de los derechos sociales, específicamente. A partir de una investigación bibliográfica deductiva, se demostró que la esfera privada no es inmune a la normatividad presente de los derechos fundamentales y, por ello, pueden tener eficacia en las relaciones en que el poder estatal no está presente. Además, se concluyó que el derecho social a la salud del transexual merece, por medio de atención médica que tenga en cuenta sus peculiaridades de cuerpo y mente, ser reconocido en la esfera privada.

PALABRAS CLABE: Derecho a la Salud; Eficacia Horizontal; Transexualidad.

\section{INTRODUÇÃO}

Recentemente, a Justiça do Estado do Pará condenou em danos morais uma empresa de plano de saúde por ter negado atendimento médico a paciente transexual. ${ }^{03} \mathrm{~A}$ ação foi ajuizada pela Defensoria Pública daquele Estado em prol da estudante Adriana Lopes. A autora pedia indenização por danos morais por ter tido negada consulta com médico da especialidade ginecológica e, com isso, interrompido tratamento médico que estava em andamento. A empresa de plano de saúde fundamentou sua negativa na afirmação de que a especialidade seria para atendimento exclusivo de pessoas do sexo feminino. Todavia, a magistrada do caso entendeu que a não autorização à consulta seria um atentado à dignidade da pessoa

${ }^{03}$ Processo ${ }^{0}$ 0001826-86.2008.8.14.0302 da $3^{\text {a }}$ Vara do Juizado Especial Cível de Belém, sentença proferida em 27/07/2012 com homologação de acordo perante a Turma Recursal em 17/02/2014. 
humana, pois, embora a ginecologia seja uma especialização da medicina que cuida, precipuamente, da saúde da mulher, tal especialidade cuida também de aspectos relativos à reprodução humana e tratamentos hormonais que podem abranger o gênero feminino e masculino. Em razão disso, a empresa foi condenada no pagamento de indenização à autora.

Essa decisão coloca em pauta o problema relativo à extensão do direito à saúde das pessoas transexuais. Embora esse tema já seja objeto de intensas discussões teóricas e, principalmente, jurisprudenciais, a presente pesquisa se direciona para um aspecto específico desse assunto, já que o direito à saúde da população transexual pode ser abordado por diversos vieses, tal como o reconhecimento de sua identidade de gênero, a subjetivação desse direito, sua judicialização, bem como a formulação de políticas públicas especialmente desenhadas para tal grupo.

A partir da decisão judicial citada, é possível perceber a existência de uma relação jurídica em que o Poder Público não estava presente, ou seja, não foi imposta obrigação de tutela ao direito social à saúde perante a esfera estatal, mas em uma relação contratual exclusiva entre particulares. Essa mudança no destinatário da obrigação de cumprimento de direitos sociais não é trivial se se levar em consideração que os direitos fundamentais foram concebidos para a proteção das ameaças provindas do Estado. Nessa perspectiva, apenas um dos participantes da relação é titular de direitos, o poder estatal figura apenas como o responsável pela implementação, sem um direito recíproco em face do cidadão - trata-se da perspectiva vertical dos direitos fundamentais. No entanto, limitar a proteção dos direitos fundamentais apenas nas relações cidadão-Estado pode vir a excluir uma parcela significativa de situações jurídicas em que o Estado não participa, todavia, as ameaças e violações a esses direitos encontram-se presentes.

A literatura jurídica nacional já avançou de maneira bastante significa no tratamento teórico do fenômeno da horizontalidade dos direitos fundamentais. $\mathrm{O}$ próprio Supremo Tribunal Federal, no RE ???, reconheceu toda a importância dessa discussão. Todavia, existe uma considerável lacuna investigativa no tocante à extensão dessa eficácia horizontal quando se está defronte de direitos fundamentais sociais, os quais carregam consigo uma nota distintiva em relação às liberdades públicas. Nesse sentido: a presente pesquisa indaga: em que medida os direitos fundamentais sociais, em especial o direito à saúde das pessoas transexuais, geram efeitos nas relações que se dão exclusivamente entre particulares? A partir dessa pergunta-problema pretende-se demonstrar que o direito social à saúde trans, assim como 
os demais direitos sociais, apesar de diferenças históricas em relação às liberdades públicas, não podem se consubstanciar em uma área imune de proteção mesmo quando o Estado não se encontra no outro polo da relação.

Esse percurso investigativo se dá a partir de levantamento bibliográfico na área de gênero e eficácia horizontal dos direitos fundamentais. Partimos ainda de proposições gerais sobre a temática (direito à saúde da população trans e eficácia horizontal dos direitos) para deduzir a extensão de tutela dos direitos sociais nas relações entre particulares.

\section{IDENTIDADE DE GÊNERO E TRANSEXUALIDADE}

A sexualidade humana compreende três aspectos distintos, a orientação afetiva sexual, o sexo e o gênero, este último é o que cada indivíduo entende a respeito do pertencimento ao mundo masculino ou feminino, isto é, a sua identidade de gênero.

Segundo os princípios de Yogyakarta, identidade de gênero é:

A profundidade sentida experiência interna e individual do gênero de cada pessoa, que pode ou não corresponder ao sexo atribuído no nascimento, incluído o senso pessoal do corpo (que pode envolver, por livre escolha, modificações da aparência ou função corporal por meio médicos, cirúrgicos ou outros) e outras expressões de gênero, inclusive vestimenta, modo de falar e maneirismos. ${ }^{04}$

Denota-se que na identidade de gênero, os indivíduos não se identificam com o seu sexo biológico. Uma vez que gênero diferencia-se de sexo, este construído biologicamente pelos cromossomos "X" e "Y" pela sociedade.

São chamados de transexuais os indivíduos caracterizados pelo desejo compulsivo de modificar seu sexo anatômico em conformidade com seu gênero psicossocial.

${ }^{04}$ PRINCÍPIO DE YOGYAKARTA. Disponível em: http://www.clam.org.br/uploads/conteudo/principios_de_yogyakarta.pdf. Acesso em: 13 mar. 2018.

${ }^{05}$ CERQUEIRA, Elizabeth Kipman (org.). Sexualidade, gênero e desafios biológicos. São Caetano do Sul: Difusão, 2011. p. 46. 
Há um conflito entre o sexo biológico, que é determinado cromossomicamente, com o gênero de sua psique. Observa-se ainda que na puberdade, ao tomar conhecimento de sua sexualidade, depara-se com um grande conflito interior caracterizado pelo repúdio aos seus órgãos sexuais, além do exterior, porquanto normalmente sofrem rejeição primeiramente no próprio âmbito familiar, ou seja, no meio em que vivem, posteriormente nas relações com o Estado e particulares ${ }^{06}$.

Ao discorrer acerca do tema, Tereza Rodrigues Vieira afirma que:

Nestes casos a evolução da identidade sexual não seguiu a via correta, tendo ocorrido uma justaposição de diversos fatores psicológicos, hormonais e sociais sobre o comportamento cromossômico [...]. Esta adequação lhe é imposta de modo irreversível, escapando ao seu livre-arbítrio ${ }^{07}$.

Para a Organização Mundial de Saúde (OMS) a transexualidade é considerada um tipo de transtorno de identidade de gênero, como consta no Cadastro Internacional de Doenças - CID 10, em sua seção F64.0, sendo uma das variações da sexualidade humana segundo a qual o indivíduo possui um "sentimento profundo de pertencer ao sexo oposto e a vontade extremada de reversão sexual"08.

Sexo e gênero são distintos. O sexo é definido pela natureza, baseado no corpo orgânico, biológico, hormonal e genético, enquanto o gênero é algo que se entende por meio de uma cultura, mais precisamente atrelado à figura do papel masculino e feminino que se exerce na sociedade ${ }^{09}$.

A transexualidade, portanto, é a discrepância do sexo com o gênero, no qual se um indivíduo nasce com o cromotipo XY (macho) ele deveria ser, pelo padrão sexual, do gênero masculino, entretanto, o transexual se entende como do gênero feminino.

Nesse sentido, Ana Paula Ariston Barion Peres ensina que:

\footnotetext{
${ }^{06}$ SNAZIAWSKI, Elimar. Limites e Possibilidade do direito de redesignação do estado sexual. São Paulo: Revista dos Tribunais, 1999. p. 49.

${ }^{07}$ VIEIRA, Tereza Rodrigues. O direito à mudança de sexo do transexual. Revista Jurídica Consulex. Ano VIII, $\mathrm{n}^{\mathrm{O}} 181,31$ de jul. 2004.

${ }^{08}$ SNAZIAWSKI, Elimar. Op. cit., p. 53.

${ }^{09}$ PERES, Ana Paula Ariston Bario. Transexualismo: O direito a uma nova identidade sexual. São Paulo: Renovar, 2001. p. 98.
} 
Embora se sinta pertencente ao outro sexo, o seu corpo espelha uma realidade diversa, e é com base no seu sexo anatômico que a sociedade lhe atribui um papel sexual e espera que ele, nesses moldes, o desempenhe. Esse papel socialmente aceitável, contudo, se torna intangível para essa pessoa. ${ }^{10}$

Por se sentirem do gênero oposto, os transexuais consideram que as relações afetivo-sexuais com seus parceiros são hetero e não homossexuais ${ }^{11}$, pois a orientação afetiva sexual dá-se pelo gênero e não pelo sexo.

Ressalte-se que a transexualidade não se confunde com a travestilidade uma vez que este se caracteriza pela vestimenta do gênero oposto e não há aversão ao sexo biológico. Tampouco se confunde com as orientações afetivas sexuais, que para os princípios de Yogyakarta compreende:

Como uma referência à capacidade de cada pessoa de ter uma profunda atração emocional, afetiva ou sexual por indivíduos de gênero diferente, do mesmo gênero ou de mais de um gênero, assim como ter relações íntimas e sexuais com essa pessoa $^{12}$.

Já o transexual repudia seu sexo biológico e a sua manutenção gera propensão à depressão e o desejo suicida em razão do intenso sofrimento psíquico ${ }^{13}$. Para alguns transexuais a cirurgia de redesignação sexual é a adequação a uma condição existente por já considerar pertencente ao gênero oposto. Para eles o procedimento cirúrgico se apresenta como uma solução para que cesse o conflito entre a sua mente e o seu corpo ${ }^{14}$.

No Brasil não há lei que discipline a cirurgia de redesignação sexual, mas esta se tornou possível por intermédio da Resolução 1.955/2010 do Conselho Federal de Medicina. A cirurgia é permitida, inclusive na rede pública de saúde, desde que haja o diagnóstico de transexualidade, assinado por uma equipe multidisciplinar e um acompanhamento de dois anos, onde o indivíduo, maior de vinte e um anos,

\footnotetext{
${ }^{10}$ PERES, Ana Paula Ariston Bario. Op. cit., p. 104.

${ }^{11}$ ZAMBRANO, Elizabeth. Parentalidade "impensáveis": pais/mães homossexuais, travestis e transexuais. Horizontes Antropológicos, v. 12, n. 26, Porto Alegre, jul./dez. 2006.

${ }^{12}$ PRINCÍPIO DE YOGYAKARTA. Disponível em: http://www.clam.org.br/uploads/conteudo/principios_de_yogyakarta.pdf. Acesso em: 13 mar. 2014.

${ }^{13}$ ARÁN, Márcia; ZAIDHAFT, Sérgio; MURTA, Daniela. Transexualidade: corpo, subjetividade e saúde coletiva. Psicologia e Sociedade, Porto Alegre, v. 20, n. 1, jan./abr. 2008.

${ }^{14}$ CONSELHO FEDERAL DE MEDICINA. Resolução CFM n ${ }^{\circ}$ 1.955/2010. Disponível em: http://www.portalmedico.org.br/resolucoes/CFM/2010/1955_2010.htm. Acesso em: 14 mar. 2014.
} 
se submeta a essas condições, apurando que ele tem condições psíquicas para a redesignação.

O indivíduo diagnosticado como transexual apresenta características como: 1) desconforto com o sexo biológico; 2) desejo expresso de eliminar os genitais, perder as características primárias e secundárias do próprio sexo e ganhar as do sexo/ gênero oposto; 3) permanência desses distúrbios de forma contínua e consistente por, no mínimo, dois anos; e 4) ausência de outros transtornos mentais ${ }^{15}$.

A cirurgia de transexuais $\mathrm{MtF}$ (Male-to-Female Transexual) ${ }^{16}$ consiste na amputação peniana para a feitura de uma vulva, além da implantação de silicone e a aplicação de hormônios femininos. Já na cirurgia FtM (Female-to-Male Transexual) ${ }^{17}$ há a amputação dos seios e a preparação de um órgão genital masculino artificial.

Entretanto, o tratamento cirúrgico é, necessariamente, precedido de parecer unânime dos profissionais que compõem o corpo clínico, que conclua pela irreversibilidade da identidade de gênero do transexual e reconheça a "supremacia do fator psicossocial na composição do sexo"18.

Ressalte-se ainda que o prenome do transexual é uma das etapas a serem transpostas, o qual possui interesse em harmonizar a característica masculina ou feminina do prenome com a sua aparência, independentemente de transgenitalização.

O transexual na busca de seus direitos legais depara-se primeiramente com uma família que o desqualifica e com uma justiça que o despersonaliza uma vez que ambos não os reconhecem, deixando-o a margem da sociedade, onde se pode visualizar a violação de direitos fundamentais e dos direitos da personalidade.

Dessa maneira, o transexual deve ser protegido com base nos princípios constitucionais da autonomia da vontade, da liberdade e da dignidade da pessoa humana, respeitando-se sua autodeterminação para assegurar-lhe a redesignação sexual por meio de cirurgia, a fim de alcançar sua realização plena como indivíduo, até porque determina o inciso IV, do art. $3^{\circ}$ da Constituição Federal que um dos objetivos da República é promover o bem-estar de todos, o que pressupõe o direito à felicidade, respaldando assim, a efetivação dos direitos da personalidade dos transexuais.

\footnotetext{
15 ARÁN, Márcia; ZAIDHAFT, Sérgio; MURTA, Daniela. Op. cit.

16 Transexual masculino para o feminino.

17 Transexual feminino para o masculino.

18 VIEIRA, Tereza Rodrigues. Op. cit.
} 
É importante ressaltar ainda que a preocupação com a tutela da identidade do transexual não envolve apenas a redesignação sexual, tal passo é importante, mas não é sentido como necessário por todos. Em razão disso, no que diz respeito à saúde da população transexual, é indispensável um tratamento especializado que advém das particularidades que envolvem os corpos e as mentes dos transexuais, é comum a necessidade de atendimento médico diante da automutilação do órgão genital, de complicações derivadas de procedimentos de modificação dos órgãos sexuais secundários (implantes caseiros) e de adversidade ocasionadas pela ingestão excessiva de hormônios. Somente por meio do reconhecimento da diferença é que se torna possível a efetivação do direito à saúde desse grupo tão vulnerável. ${ }^{19}$

Por fim, os postulados que embasam o sistema de saúde no país (universalidade, integralidade e equidade) impõem uma visão aos profissionais da área que consiga visualizar a peculiaridade inerente aos transexuais em relação à sua não compatibilidade entre a identidade de gênero e sexo biológico.

Dessa maneira, a tutela do direito social à saúde dos transexuais precisa ser problematizada à luz da teoria da eficácia horizontal, para que se investigue a potencialidade de que esse atendimento diferenciado também possa ser imposto em uma relação traçada exclusivamente entre particulares.

\section{EFICÁCIA DOS DIREITOS SOCIAIS NAS RELAÇÕES ENTRE PARTICULARES}

A estrita separação entre Estado e Sociedade no pós-revoluções burguesas se deu por meio da concessão aos indivíduos de direitos fundamentais concebidos originariamente para afastar as violações que partiam do Estado. Nesse sentido, os direitos fundamentais seriam o ponto extremo perante o qual as ações estatais não poderiam ultrapassar. Essas conquistas permitiram, portanto, um amplo espaço de liberdade e autonomia nas relações travadas entre os particulares, principalmente naquelas de caráter patrimonial. A razão de ser dessa abstenção estatal, além da suposição de que as ações privadas estariam sob o manto da igualdade (formal), o que dispensava qualquer atenção do Estado, encontrava-se na necessidade da expansão capitalista à época. Denota-se, assim, que o único destinatário dos direitos fundamentais seria o Estado, pois dele viriam as ameaças à liberdade e autonomia

\footnotetext{
${ }_{19}$ Para uma análise mais detalhada a respeito do atendimento especializado à saúde dos transexuais: BRIGANTINI, Raquel Barbero. Da Transexualidade: Políticas Públicas de Saúde. Trabalho de Conclusão de Curso. Universidade Estadual do Norte do Paraná, 2013.
} 
privada. Nesse ponto é que se diz que os direitos fundamentais teriam uma eficácia vertical, ou seja, a oponibilidade exclusiva em face dos órgãos estatais, únicos sujeitos obrigados a respeitar tais direitos. Essa noção enraizou-se na teoria e prática constitucionais, principalmente as dos ordenamentos vinculados ao modelo liberal.

Ocorre, todavia, que essa construção não se tem demonstrado compatível com a realidade. Dizer que os direitos fundamentais obrigam apenas o respeito por parte do Estado é minimizar o potencial garantidor que essas normas carregam em sua essência. Além disso, as ameaças aos direitos fundamentais não se originam somente do Estado. As relações de poder estão disseminadas por toda a sociedade: megagrupos industriais, comerciais, financeiros e midiáticos, capazes de impor seus modelos de políticas econômicas em face dos Estados ${ }^{20}$, e que, de alguma forma, acabam condicionando, restringindo ou até mesmo eliminando a liberdade dos indivíduos. Em razão disso, esses agentes têm recebido a denominação de poderes privados. ${ }^{21}$ Tais poderes representam uma ameaça aos direitos fundamentais não menor do que a representada nas ações estatais, quiçá podem ser até mais perigosos que os poderes públicos, uma vez que são favorecidos pelas dificuldades existentes para articular um sistema incisivo de controle de suas ações ${ }^{22}$.

Desse modo, a eficácia vertical dos direitos fundamentais é insuficiente diante da pulverização das violações a esses direitos. Tutelar os direitos fundamentais apenas quando eles são desrespeitados pelo Estado é realizar uma proteção incompleta, pois deixa de vislumbrar os mais variados abusos perpetrados na esfera privada, protegida pela concepção liberal dos direitos. Os direitos fundamentais, pois, são respostas contra as diversas ameaças contra o homem, e a mutabilidade delas impõe o desenvolvimento de novos instrumentos que ultrapassem a proteção da relação Estado-cidadão. Atribui-se, portanto, aos direitos fundamentais uma vertente denominada de eficácia horizontal. Pretende-se enfocar com essa expressão a tese de que os direitos fundamentais não são oponíveis exclusivamente em face do poder estatal, mas também em relação aos particulares. Importa destacar que essa

\footnotetext{
$\overline{{ }^{20}}$ STEINMETZ, Wilson. A vinculação dos particulares a direitos fundamentais. São Paulo: Malheiros, 2004. p. 88.

${ }^{21}$ Importa destacar nesse ponto a crítica feita por Jorge Reis Novais no que diz respeito à atualidade da tomada de consciência da ameaça dos poderes privados. Para esse autor, "a consciência dessas ameaças esteve sempre presente e o Estado liberal sempre procurou dar-lhe a resposta considerada adequada na época". NOVAIS, Jorge Reis. Direitos fundamentais: trunfos contra a maioria. Coimbra: Coimbra, 2006, p. 84. Ainda de acordo com seu raciocínio, a preocupação com as ameaças sociais (de terceiros) à propriedade estava consubstancia$\mathrm{da}$, institucionalmente, na reserva do direito ao voto da minoria detentora daquele direito, para que nunca houvesse a permissão legal de violação da propriedade.

${ }^{22}$ BILBAO UBILLOS, Juan María. La eficacia de los derechos fundamentales frente a particulares: análisis de la jurisprudencia del Tribunal Constitucional. Madrid: Centro de Estudios Políticos y Constitucionales, 1997. p. 243.
} 
vinculação não se dá somente contra os poderes privados, pois alberga, além deles, as relações em que não há subordinação, ou seja, nos vínculos igualitários, pois não importando de onde provenha a violação, mas a tutela do direito fundamental agredido.

A origem da discussão dos direitos fundamentais nas relações entre particulares tem raiz no direito germânico ${ }^{23}$ a partir da segunda metade do século XX por meio da doutrina da "Drittwirkung der Grundrechte", ou seja, efeitos frente a terceiros dos direitos fundamentais, formulada pelo juiz do Tribunal Federal do Trabalho da Alemanha Hans Carl Nipperdey. Segundo Bilbao Ubillos ${ }^{24}$, Nipperdey traz em sua teoria a consciência do poder social e econômico de determinados grupos privados, poder esse capaz de afetar intensamente um grande número de indivíduos. Em razão disso, há preceitos que reconhecem direitos fundamentais frente a esses poderes privados. Não é de se estranhar, ainda, que a gênese teórica se encontre em um tribunal em que a força dos poderes privados é mais evidente, pois é nas relações de trabalho que se vislumbram mais claramente as violações dos direitos fundamentais dos particulares por meio de outro particular.

Dentro do fenômeno da horizontalidade dos direitos fundamentais pode-se ainda aprofundar sua análise para a visualização de uma problemática específica que diz respeito aos direitos sociais. Melhor dizendo, o debate em torno dos direitos fundamentais e sua eficácia nas relações entre particulares, apesar de estar longe de se tornar uma prática constante nos tribunais pátrios, alcançou, no âmbito doutrinário, uma considerável aceitação no sentido de que esses direitos atingem, de alguma forma, as tratativas privadas ${ }^{25}$. Não se pode perder de vista, todavia, que o terreno é fértil e não completamente aclarado, haja vista as implicações que a aceitação dessa teoria pode gerar no extenso direito civil brasileiro, nas normas de direito empresarial, no debate processual e internacional da temática.

Verifica-se, no entanto, que a discussão da eficácia horizontal dos direitos

\footnotetext{
${ }^{23}$ A razão do problema da eficácia horizontal ser uma construção "made in Germany" está no cunho liberal (proteção contra as violações estatais) da Constituição alemã a despeito da caracterização de "Estado Social e Democrático" contida no art. 20,1. "Qualquer extensão desse âmbito de aplicação a outros tipos de relação que não as indivíduo-Estado, exige uma fundamentação que não é trivial. [...] e é por isso, também, que quase todas as teorias para a reconstrução do problema foram desenvolvidas por autores alemães, que tinham que superar dificuldades e limites do texto constitucional alemão que não estavam presentes em outros países". SILVA, Virgílio Afonso da. A Constitucionalização do Direito: os direitos fundamentais nas relações entre particulares. São Paulo: Malheiros, 2005, p. 23.

${ }^{24}$ BILBAO UBILLOS, Juan María. Op. cit., p. 271.

${ }^{25}$ SARLET, Ingo Wolfgang. Direitos fundamentais sociais, "mínimo existencial" e direito privado: breves notas sobre alguns aspectos da possível eficácia dos direitos sociais nas relações entre particulares. In: SARMENTO, Daniel; GALDINO, Flávio (org.). Direitos fundamentais: estudos em homenagem ao professor Ricardo Lobo Torres. Rio de Janeiro: Renovar, 2006, p. 579.
} 
fundamentais restringe-se, principalmente, apenas aos direitos de defesa, ou seja, àqueles direitos em que há mero dever de abstenção de agir, tanto dos poderes públicos, como dos particulares: imposição de não-discriminação, possibilidade de exercício de ampla defesa, tratamento igualitário, liberdade religiosa e associativa. Estes são os direitos normalmente atingidos nas relações que se dão exclusivamente entre os agentes privados que comportam tutela por meio da eficácia horizontal. Entretanto, o problema não se encerra por aí, pelo contrário, o caráter multifuncional dos direitos fundamentais impõe diversas formas de atuação para que a sua proteção se torne real e efetiva. Dessa maneira, sobre a proteção dos direitos sociais nas relações particulares, indaga-se: Haveria alguma responsabilidade por parte dos estabelecimentos de ensino particulares para com o direito fundamental à educação dos mais carentes? Se sim, qual o limite? Ainda mais, haveria prevalência desse mesmo direito fundamental em face da inadimplência do aluno? A respeito do direito à saúde, poderia um hospital privado ser compelido a atender pessoas sem meios suficientes para a subsistência diante de um problema de saúde? Até que ponto os contratos de assistência médica privada limitariam o gozo pleno do direito à saúde? ${ }^{26}$ Qual a obrigação das empresas privadas em proporcionar meios de trabalho aos portadores de deficiência? Ou ainda, poderia se exigir de uma rede de supermercado condições especiais para as compras realizadas pelos deficientes visuais, por exemplo, leitores ópticos que emitem som dos valores dos produtos ou informação em código Braille? As hipóteses de aplicação dos direitos sociais prestacionais às relações privadas são infindáveis, o que se pode perceber à primeira vista é que esse fenômeno se apresenta ainda mais delicado do que o que diz respeito aos direitos fundamentais em sua dimensão defensiva. Por isso, impor prestações ativas por meio dos particulares é tarefa que exige uma análise cautelosa para que não se asfixie a liberdade humana. Não bastassem as diversas possibilidades de investigação em torno da eficácia horizontal dos direitos sociais, acrescenta-se o problema do qual a presente investigação parte, qual seja, a partir dos fundamentos da horizontalidade, investigar os seus efeitos em relação ao direito à saúde dos transexuais.

A Constituição Federal de 1988 foi generosa e ao mesmo tempo ambiciosa no que diz respeito à concessão de direitos fundamentais por meio do extenso rol desses direitos, da garantia de aplicabilidade imediata, da proteção contra o constituinte derivado por meio das cláusulas pétreas e do controle amplo de constitucio-

\footnotetext{
${ }^{26}$ CRUZ, Álvaro Ricardo de Souza. Um Olhar Crítico-Deliberativo sobre os Direitos Sociais no Estado Democrático de Direito. In: SOUZA NETO, Cláudio Pereira de; SARMENTO, Daniel. Direitos Sociais: Fundamentos, Judicialização e Direitos Sociais em Espécie. Rio de Janeiro: Lumen Juris, 2010, p. 99.
} 
nalidade. O texto constitucional, para além da concepção exclusivamente vertical dos direitos fundamentais, estendeu os efeitos de tais direitos para a proteção em face dos agentes particulares, como é o caso dos direitos fundamentais dos trabalhadores, que têm em sua gênese o amparo diante das violações perpetradas pelos empregadores. No que diz respeito aos direitos sociais prestacionais, a Constituição de 1988 deu sinais de que esses direitos não seriam tarefas exclusivas do Poder Público, ou seja, dispôs em algumas normas uma nota de corresponsabilidade no tocante à sua concretização, são exemplos os artigos: 194, 205, 227 e 230.

Tais disposições não podem deixar de ser levadas em conta quando se investiga os direitos sociais nas relações particulares. O texto constitucional é expresso no sentido de atribuir deveres à sociedade na promoção dos direitos sociais à assistência, educação, proteção à criança, ao adolescente, ao jovem e aos idosos. Em que pese haver comando constitucional nesse sentido, as dificuldades para especificar o alcance e os limites dessa intervenção dos direitos fundamentais ainda são grandes.

No caso brasileiro não se tem disposição normativa a respeito da possibilidade de eficácia horizontal dos direitos fundamentais, tal como outras constituições do mundo (por exemplo: Constituição de Portugal, art. $18^{\circ}, \mathrm{n}^{\mathrm{o}} 1$ ), ou seja, não se permite expressamente, todavia, também não há proibição. Além disso, a dimensão objetiva ${ }^{27}$ inerente aos direitos fundamentais impede que se forme um gueto na realidade social em que tais direitos não sejam respeitados. Isso porque, eles são decisões básicas e estruturantes do Estado e da sociedade. Tais direitos formam um sistema protetivo que, apesar das diversas formas como podem ser

\footnotetext{
${ }_{27}$ Para maior desenvolvimento da temática, indica-se o texto: LIMA, Jairo Néia. A horizontalidade dos direitos fundamentais por meio da sua dimensão objetiva. In: AGOSTINHO, Luis Otávio Vincenzi; HERRERA, Luiz Henrique Martim. (org.). Tutela dos Direitos Humanos e Fundamentais: ensaios a partir das linhas de pesquisa Construção do Saber Jurídico e Função Política do Direito. Birigüi: Boreal, 2011, p. 154-168.
} 
positivados $^{28}$ e concretizados, estão ligados pelo objetivo comum a ser perseguido que é a dignidade da pessoa humana. Em princípio não há óbice para que os direitos sociais prestacionais não se estendam às relações privadas simplesmente por exigirem ações positivas. Por outro lado, não se descuida de que a afirmação genérica dessa vinculação exige mais atenção no que se refere às formas pelas quais os particulares irão cumprir esses comandos. Contudo, esse fato, por si só, não pode ser obstáculo instransponível para a projeção dos direitos sociais prestacionais às relações privadas.

No âmbito da doutrina brasileira específica do tema, Wilson Steinmetz ${ }^{29}$ entende por incorreta a tese de que também os direitos sociais prestacionais operam eficácia no âmbito das relações entre particulares. Para ele, as prestações dos direitos sociais obrigam apenas o Estado, eximindo os particulares de qualquer atuação nesse sentido, exceto no que diz respeito aos direitos fundamentais sociais dos trabalhadores que, para ele, vinculariam os particulares. Ocorre que essa horizontalidade não agrega nada de novo a tais direitos, pois a origem destes é a proteção em face dos agentes privados. Ainda mais, se por um lado a tese negativa do autor parte da crítica à afirmação genérica de que todos os direitos fundamentais se aplicam às relações privadas, por outro, seu argumento de rechaço acaba sendo

\footnotetext{
${ }^{28}$ Carlos Bernal Pulido aponta a indeterminação do objeto como uma das características que diferencia os direitos sociais. A esse respeito, ele afirma: "Nos direitos sociais, a indeterminação se apresenta porque a disposição que estabelece o direito não fixa com clareza em todos os casos qual é a prestação mediante a qual se satisfaz o direito. Como consequência, tampouco aparece determinado o que é considerado constitucionalmente contrário aquilo que o direito exige, ou seja, não aparece determinado quando se vulnera o direito social". PULIDO, Carlos Bernal. Fundamento, Conceito e Estrutura dos Direitos Sociais: Uma Crítica a "Existem direitos sociais?" de Fernando Atria. In: SOUZA NETO, Cláudio Pereira de; SARMENTO, Daniel. Direitos Sociais: Fundamentos, Judicialização e Direitos Sociais em Espécie. Rio de Janeiro: Lumen Juris, 2010 p. 150-151. No entanto, tal argumento pode servir à ineficácia desses direitos em razão do aspecto difuso a eles atribuído. Para fins de alcançar sua eficácia, Vidal Serrano Júnior faz uma análise das diversas formas pelas quais os direitos sociais são positivados no Texto Constitucional. Para ele, tais direitos são positivados por meio de: a) normas programáticas que se limitam a apontar diretrizes, tarefas ou finalidades a serem atingidas, sem, contudo, precisar como, quando e o que deve exatamente ser feito, como o art. 230 que trata da proteção ao idoso; b) normas atributivas de direitos públicos subjetivos, como o art. 205 c.c. o art. 208 que elenca as formas pelas quais a educação, como dever do Estado, será garantida; c) normas consagradoras de garantias institucionais tanto as de índole político-jurídicas (municípios, associações, partidos políticos) como as de caráter de direito privado como a família e a propriedade (art. $182, \S 4^{\circ}$, III e art. 184 que se referem à desapropriação para preservação da função social da propriedade); d) cláusulas limitativas do poder econômico, como os direitos dos trabalhadores e a proteção ao consumidor; e) normas projectivas, ou seja, normas de conformação do perfil social dos institutos fundantes da ordem econômica capitalista, tais normas têm o condão de compatibilizar os preceitos essencialmente capitalistas com o perfil social da Constituição de 1988, note-se o art. 170 que trata da ordem econômica, mas limita a sua atuação aos princípios humanizadores que traz em seus incisos, com o objetivo último de propiciar uma vida digna. Dessa forma, alcança-se uma delimitação mínima a fim de que os direitos sociais possam ser juridicamente exigíveis, superando, assim, a obscuridade de sua área de proteção. NUNES JUNIOR, Vidal Serrano. A Cidadania Social na Constituição de 1988 - Estratégias de Positivação e Exigibilidade Judicial dos Direitos Sociais. São Paulo: Verbatim, 2009, p. 98 et seq.
}

${ }^{29}$ STEINMETZ, Wilson. Op. cit., p. 278-279. 
também demasiado amplo, pois não considera as formas específicas pelas quais os direitos sociais podem ser aplicados às relações privadas.

Em que pese a discussão dessa temática não ter alcançado ainda muitos adeptos, e levando-se em conta a premissa teórico-constitucional sobre a qual parte esse trabalho, não há como excluir de forma absoluta os particulares das obrigações provindas dos direitos sociais prestacionais, haja vista que o projeto de sociedade que a Constituição Federal visa ultrapassa o individualismo egocêntrico que norteia os interesses privados. A construção de uma sociedade livre, justa e solidária é um dever do Estado, mas que também pesa sobre toda a sociedade na medida de suas responsabilidades $^{30}$. No mesmo sentido, Jörg Neuner ${ }^{31}$ afirma que não faz diferença de onde provenha a violação à dignidade humana, se pública ou privada, os direitos fundamentais sociais ensejam, sim, uma eficácia horizontal, pois recepcionam um padrão mínimo de humanização das relações privadas.

Deve-se deixar claro que o modo como seriam aplicados os direitos fundamentais nas relações entre particulares não seria igual ao que se aplica às obrigações de políticas públicas a cargo do Estado. Não se pode simplesmente substituir o Estado como destinatário de um direito fundamental por um particular, e exigir desse as mesmas prestações. Já foi explicado, pois, que nas relações privadas há sempre dois titulares de direitos fundamentais. Assim, a eficácia horizontal sempre envolverá um conflito de direitos fundamentais que não possibilita soluções a priori sem levar em conta as peculiaridades dos casos concretos. Mesmo assim, essa elevada dose de prudência e bom senso no reconhecimento de direitos subjetivos a prestações, tendo por destinatário os particulares, não poderá, por si só, levar à negação dessa possibilidade ${ }^{32}$. A confirmar a eficácia horizontal dos direitos sociais, Gregorio Peces-Barba Martínez (tradução nossa) afirma:

Os direitos econômicos, sociais e culturais estabelecem em favor dos seus titulares uma prestação normalmente a cargos dos poderes públicos, ainda que, em ocasiões, podem estar a cargo de outros particulares. São muitas vezes vistos como direitos de crédito, ao outorgar aos titulares um título para

\footnotetext{
${ }^{30}$ SARMENTO, Daniel. Direitos Fundamentais e Relações Privadas. 2. ed. Rio de Janeiro: Lumen Juris, 2006a, p. 297.

${ }^{31}$ NEUNER, Jörg. Os direitos humanos sociais. In: SARLET, Ingo Wolfgang (coord.). Jurisdição e Direitos Fundamentais: anuário 2004/2005. Escola Superior da Magistratura do Rio Grande do Sul - AJURIS. Porto Alegre: Escola Superior da Magistratura: Livraria do Advogado, 2006, p. 164.

32 SARLET, Ingo Wolfgang. Op. cit., p. 592.
} 
exigir essa prestação de quem resulte obrigado. A justificativa da intervenção baseia-se na convicção de que resolve uma carência, em relação com uma necessidade básica, que impede o desenvolvimento como pessoa e a livre eleição de planos de vida de quem se encontre nessa situação. ${ }^{33}$

Observa-se, portanto, que a permissão de influência dos direitos fundamentais junto às relações privadas denota uma corresponsabilidade com a diminuição das desigualdades sociais, sem excluir a obrigação primária do Estado. É importante salientar que não se pretende isentar os órgãos públicos do planejamento e execução das políticas públicas necessárias e urgentes para a sociedade brasileira tão desigual e excludente. Ocorre, no entanto, que a convivência em sociedade une os indivíduos em prol de um objetivo político comum, expresso na Constituição. Resguarda-se a liberdade individual para perseguir as vontades e projetos pessoais, ${ }^{34}$ mas isso não pode ser um escudo protetor para que os agentes privados se eximam de colaborar para a maximização da dignidade humana de cada indivíduo.

As principais teorias que foram elaboradas com o intuito de explicar a forma pela qual os efeitos dos direitos fundamentais chegariam às relações privadas não têm uma causalidade sucessiva entre elas, uma vez que muitas delas partem do mesmo ponto, mas chegam a conclusões opostas. Assim, a presente investigação restringir-se-á apenas às duas principais teorias ${ }^{35}$, quais sejam: teoria da eficácia indireta e direta.

A teoria da eficácia indireta ou mediata dos direitos fundamentais nas relações entre particulares foi formulada por Günther Dürig na doutrina alemã, em

\footnotetext{
33 "Los derechos económicos sociales y culturales establecen en favor de sus titulares una prestación normalmente a cargo de los poderes públicos, aunque, en ocasiones, pueden estar a cargo de otros particulares. Se les suele considerar como derechos de crédito, al otorgar a los titulares un título para exigir esa prestación de quién resulte obligado. La justificación de la intervención se basa en la convicción de que resuelve una carencia, en relación con una necesidad basica, que impide el desarrollo como persona y la libre elección de planes de vida de quien se encuentre en esa situación". MARTínEZ, Gregorio Peces-Barba. Derechos sociales y positivismo jurídico (Escritos de Filosofía Jurídica y Política). Instituto de Derechos Humanos Bartolomé de las Casas. Madrid: Dykinson, 1999, p. 60.

${ }^{34}$ A respeito dessa liberdade, Vieira de Andrade diz: "o homem não é apenas um ser racional, nem é perfeito e a ética jurídica não pode pretender que ele o seja. A liberdade do homem individual inclui necessariamente uma margem de arbítrio, é também uma liberdade emocional". VIEIRA DE ANDRADE, José Carlos. Os direitos, liberdades e garantias no âmbito das relações entre particulares. In: SARLET, Ingo Wolfgang (org.). Constituição, Direitos Fundamentais e Direito Privado. 2. ed. Porto Alegre: Livraria do Advogado, 2006, p. 297.

35 As demais teorias são: Stateaction, teoria dos deveres de proteção e teoria da convergência estatista.
} 
obra publicada em 1956. Essa concepção foi acolhida no paradigmático caso Lüth. ${ }^{36}$ Tornou-se, ainda, posição dominante entre os juristas e a Corte Constitucional daquele país. ${ }^{37}$ Para os adeptos dessa teoria, os direitos fundamentais representam uma ordem objetiva de valores que deve irradiar os seus efeitos sobre as relações entre particulares. Todavia, essa relação não se pode dar de maneira direta, pois se exige uma medida intermediária para que esses direitos atinjam esse tipo de relação. Tal medida concretizadora deve partir inicialmente do legislador na produção do direito infraconstitucional privado em conformidade com os direitos fundamentais e, em um segundo momento, caberia aos julgadores a tarefa de infiltrar os direitos fundamentais nas relações privadas por meio da interpretação das cláusulas gerais e dos conceitos abertos, como boa-fé, moral, bons costumes, etc. Segundo Bilbao Ubillos $^{38}$ (tradução nossa), "as cláusulas gerais e os conceitos jurídicos indeterminados seriam as zonas ou 'ponto de irrupção', as brechas de entrada dos valores que servem os direitos fundamentais no Direito civil". ${ }^{39}$ Sendo assim, o próprio direito privado forneceria o material normativo suficiente para delimitar o âmbito de incidência dos direitos fundamentais nesse tipo de relação.

\footnotetext{
${ }^{36}$ Em 1950, o presidente do clube de imprensa de Hamburgo, Erich Lüth, expressou-se publicamente (defendendo um boicote) contra um filme que seria apresentado em um festival cinematográfico. Tal filme era dirigido por Veit Harlan que, na época do regime nazista, havia dirigido filmes antissemitas e de cunho propagandístico para o regime em vigor. O produtor do filme ajuizou ação no sentido de exigir indenização civil e de fazer cessar as manifestações de Lüth, o pleito foi concedido com fundamento no $\S 826$ do Código Civil alemão, pois entendeu-se que a incitação ao boicote contrariava os bons costumes. Ao recorrer ao Tribunal Constitucional, Lüth conseguiu assegurar o seu direito fundamental à manifestação de pensamento naquela civil (no caso em comento: "os bons costumes") estão influídas pelos direitos fundamentais, demonstrando assim a irradiação de efeitos das normas constitucionais perante a legislação privada. GARCÍA TORRES, Jesús; JIMENÉZ-BLANCO, Antonio. Derechos fundamentales y relaciones entre particulares. La Drittwirkung en la jurisprudencia del Tribunal Constitucional. Madrid: Editorial Civitas, 1986, p. 26-31.

${ }^{37}$ Jane Reis Gonçalves Pereira aponta a justificativa pela qual a teoria da eficácia indireta é dominante na jurisprudência alemã. Em terras germânicas o problema da eficácia horizontal liga-se diretamente à questão processual do fenômeno, pois o sistema concentrado de controle de constitucionalidade juntamente com o recurso constitucional geram os seguintes problemas: "uma vez admitida a incidência direta dos direitos fundamentais no direito privado, é necessário reconhecer a competência do órgão encarregado de exercer a jurisdição constitucional para examinar tais conflitos. Isto significa dizer que o recurso constitucional passaria a ser usado com maior frequência, pois derrubadas as barreiras entre direito privado e direito público, seria possível recorrer à Corte Constitucional em uma infinidade de disputas jurídicas privadas. Questiona-se se isso não poderia acarretar, em última análise, a transformação dos tribunais constitucionais em instâncias supremas de resolução de conflitos jurídico civis, o que implicaria uma sobrecarga de trabalho para estes e esvaziaria o papel que lhes fora originariamente conferido". PEREIRA, Jane Reis Gonçalves. Apontamentos sobre a Aplicação das Normas de Direito Fundamental nas Relações Jurídicas entre Particulares. In: BARROSO, Luis Roberto (Org.). A nova interpretação constitucional: ponderação, direitos fundamentais e relações privadas. Rio de Janeiro: Renovar, 2006, p. 169.

${ }^{38}$ BILBAO UBILLOS, Juan María, op. cit., p. 305.

39 'Las cláusulas generales y los conceptos jurídicos indeterminados serían las zonas o 'punto de irrupción', las brechas de entrada de los valores a los que sirven los derechos fundamentales en el Derecho civil". BILBAO UBILLOS, op. cit., p. 305.
} 
No contexto da teoria da eficácia indireta, o Tribunal Constitucional alemão, ao decidir o caso Lüth, levou em conta que a interpretação do preceito privado "contrário aos bons costumes" só poderia legitimar-se a partir do momento que estivesse em consonância com os direitos fundamentais, no referido caso, o direito fundamental à liberdade de expressão. A doutrina jurídica traz outro exemplo de eficácia indireta: trata-se da nulidade de uma cláusula contratual pela qual alguém se obriga a deixar de exercer seu direito fundamental à liberdade religiosa, nesse caso ocorreria a contrariedade ao preceito de direito privado ordem pública que teria sido preenchido com o conteúdo do direito fundamental violado ${ }^{40}$.

No que diz respeito aos direitos fundamentais sociais, não é nenhuma novidade a existência de legislação intermediadora, no sentido de conceder esses direitos por meio de uma iniciativa particular. Um exemplo digno de nota pode ser encontrado na Lei $\mathrm{n}^{0}$ 11.096/2005, que instituiu o Programa Universidade para Todos (PROUNI). Tal legislação impõe a concretização do direito social à educação aos estudantes egressos de escolas públicas, bem como aos portadores de deficiência, mediante a concessão de bolsas de estudos em universidades particulares. Estas, por sua vez, recebem isenção fiscal para promover a inclusão daqueles que nunca tiveram a oportunidade de acesso a esse espaço social de conhecimento e emancipação. Ainda na esfera da educação, a Lei n ${ }^{0} 9.870 / 1999$ dispõe sobre ao valor das mensalidades escolares e tutela, em seu art. $6^{\circ}$, o educando em face do inadimplemento contratual. Assim dispõe: "Art. 6o São proibidas a suspensão de provas escolares, a retenção de documentos escolares ou a aplicação de quaisquer outras penalidades pedagógicas por motivo de inadimplemento, sujeitando-se o contratante, no que couber, às sanções legais e administrativas, compatíveis com o Código de Defesa do Consumidor, e com os arts. 177 e 1.092 do Código Civil Brasileiro, caso a inadimplência perdure por mais de noventa dias. $\S 1^{\circ} \mathrm{O}$ desligamento do aluno por inadimplência somente poderá ocorrer ao final do ano letivo ou, no ensino superior, ao final do semestre letivo quando a instituição adotar o regime didático semestral. $\S 2^{\circ}$ Os estabelecimentos de ensino fundamental, médio e superior deverão expedir, a qualquer tempo, os documentos de transferência de seus alunos, independentemente de sua adimplência ou da adoção de procedimentos legais de cobranças judiciais".

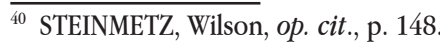


Não se pode deixar de indicar, também, a Lei no $8.899 / 94$, que concede às pessoas portadoras de deficiência, comprovadamente carentes, passe livre no sistema de transporte coletivo interestadual. Tal legislação foi objeto de ação direta de inconstitucionalidade (ADI 2649/DF), julgada improcedente pelo Supremo Tribunal Federal. ${ }^{41}$ Ainda no que diz respeito ao transporte coletivo, o Estatuto do Idoso (Lei $\left.\mathrm{n}^{\mathrm{o}} 10.471 / 03\right)$ prevê a concessão de duas vagas gratuitas aos idosos maiores de 65 anos e com renda igual ou inferior a dois salários-mínimos, além de desconto de 50\%, no mínimo, no valor das passagens, em caso de esgotamento das gratuitas.

Ainda mais, o direito à proteção à maternidade e à infância, no âmbito privado, também é tutelado por meio do artigo 399 da Consolidação das Leis do Trabalho, que assim dispõe: "O Ministro do Trabalho, Indústria e Comércio conferirá diploma de benemerência aos empregadores que se distinguirem pela organização e manutenção de creches e de instituições de proteção aos menores em idade pré-escolar, desde que tais serviços se recomendem por sua generosidade e pela eficiência das respectivas instalações". Além dessa disposição, a Lei n ${ }^{0}$ 11.770/2008 que criou o Programa Empresa Cidadã com o intuito de prorrogar a licença-maternidade por mais sessenta dias, mediante incentivos fiscais. No âmbito da assistência social, a Lei $\mathrm{n}^{\mathrm{o}}$ 8.742/93 (Lei Orgânica da Assistência Social) enuncia em seu artigo $1^{\circ}$ que "A assistência social, direito do cidadão e dever do Estado, é Política de Seguridade Social não contributiva, que provê os mínimos sociais, realizada através de um conjunto integrado de ações de iniciativa pública e da sociedade, para garantir o atendimento às necessidades básicas" (grifo nosso) e complementa no artigo 26: "O incentivo a projetos de enfrentamento da pobreza assentar-se-á em mecanismos de articulação e de participação de diferentes áreas governamentais e em sistema de cooperação entre organismos governamentais, não governamentais e da sociedade civil." (grifo nosso). Ora, esse texto infraconstitucional acolhe, de forma expressa, a participação

41 Ação direta de inconstitucionalidade: Associação Brasileira das Empresas de Transporte Rodoviário Intermunicipal, Interestadual e Internacional de Passageiros - ABRATI. Constitucionalidade da Lei 8.899, de 29 de junho de 1994, que concede passe livre às pessoas portadoras de deficiência. Alegação de afronta aos princípios da ordem econômica, da isonomia, da livre iniciativa e do direito de propriedade, além de ausência de indicação de fonte de custeio (arts. $1^{\circ}$, IV; $5^{\circ}$, XXII; e 170 da CF): improcedência. A autora, associação de classe, teve sua legitimidade para ajuizar ação direta de inconstitucionalidade reconhecida a partir do julgamento da ADI 3.153-AgR, Rel. Min. Celso de Mello, DJ de 9-9-2005. Pertinência temática entre as finalidades da autora e a matéria veiculada na lei questionada reconhecida. Em 30-3-2007, o Brasil assinou, na sede da ONU, a Convenção sobre os Direitos das Pessoas com Deficiência, bem como seu Protocolo Facultativo, comprometendo-se a implementar medidas para dar efetividade ao que foi ajustado. A Lei 8.899/1994 é parte das políticas públicas para inserir os portadores de necessidades especiais na sociedade e objetiva a igualdade de oportunidades e a humanização das relações sociais, em cumprimento aos fundamentos da República de cidadania e dignidade da pessoa humana, o que se concretiza pela definição de meios para que eles sejam alcançados. (ADI 2.649, Rel. Min. Cármen Lúcia, julgamento em 8-5-2008, Plenário, DJE de 17-10-2008). 
privada na esfera de promoção dos direitos que possibilitam a redução da pobreza e miséria. Por fim, também é exemplo o art. 93, caput, da Lei no 8.213/91, que obriga as empresas com mais de 100 empregados a contratar pessoas portadoras de deficiência.

Da análise das referidas legislações, não restam dúvidas, portanto, de que os direitos sociais se aplicam às relações privadas e que tal vinculação já se dá de forma indireta. Essas disposições normativas indicam a correponsabilidade na concretização dos direitos sociais, não exime o dever estatal, mas conclama a participação dos agentes privados. ${ }^{42} \mathrm{~A}$ respeito disso, as reflexões de Sarmento tornam-se esclarecedoras:

Existe uma série de razões que justifica, hoje, a concepção de que, ao lado do dever primário do Estado, de garantir os direitos sociais, é possível, também visualizar um dever secundário da sociedade de assegurá-los. Em primeiro lugar, porque as relações privadas, que se desenvolvem sob o pálio da Constituição, não estão isentas da incidência dos valores constitucionais, que impõem sua conformação a parâmetros materiais de justiça, nos quais desponta a ideia de solidariedade. Além disso, diante da decantada crise de financiamento do Welfare State, que o impede de atender a todas as demandas sociais relevantes, é importante encontrar outros corresponsáveis que - sem exclusão da obrigação primária do Estado - possam contribuir para amenizar o dramático quadro de miséria hoje existente, assumindo tarefas ligadas à garantia de condições mínimas para os excluídos, não já, agora, por caridade ou filantropia, mas no cumprimento de deveres juridicamente exigíveis ${ }^{43}$.

Dentro do mesmo contexto de surgimento da teoria da eficácia indireta, contrapõe-se a teoria da eficácia direta ou imediata dos direitos fundamentais nas

\footnotetext{
${ }_{42}$ A participação dos empresários em prol da concretização de direitos que possibilitam a transformação da realidade social foi objeto de estudo realizado pelo Instituto Ethos de Empresas e Responsabilidade Social. Nessa pesquisa, analisaram-se as quinhentas maiores empresas do Brasil e suas respectivas ações afirmativas no âmbito social, racial e de gênero. Em que pese a iniciativa cada vez mais comprometida de alguns setores empresariais, os dados levantados demonstraram que ainda é incipiente o comprometimento nessa tarefa inclusiva. Exemplificando, a pesquisa mostra que a grande maioria das empresas não possui qualquer medida para incentivar as mulheres, os negros e as pessoas com mais de 45 anos para participar do mercado de trabalho. INSTITUTO ETHOS DE EMPRESAS E RESPONSABILIDADE SOCIAL. Perfil Social, Racial e de Gênero das 500 maiores empresas do Brasil e suas ações afirmativas. São Paulo, 2010, p. 26.

${ }^{43}$ SARMENTO, Daniel, op. cit., p. 295.
} 
relações entre particulares. Essa ideia surgiu com as formulações de Hans Carl Nipperdey, juiz do Tribunal Federal do Trabalho alemão. Para a teoria da eficácia direta, os direitos fundamentais, como ordem objetiva de valores, devem expandir os seus efeitos sobre todo o ordenamento jurídico, inclusive o direito privado. Desse modo, as relações entre particulares não estariam imunes aos ditames constitucionais. Ocorre que, diversamente da teoria da eficácia indireta, essa incidência junto às relações privadas não se daria por meio de uma medida intermediária do legislador ou do juiz, pois os direitos fundamentais se consubstanciariam como normas diretamente aplicáveis, fundamentadoras de soluções para os conflitos que envolvessem direitos fundamentais entre agentes privados. Nipperdey entende ainda que os pontos de infiltração (cláusulas gerais) são dispensáveis para as normas constitucionais, pois o ordenamento jurídico é uma unidade, todo direito somente é válido com base na Constituição. Assim, os indivíduos podem recorrer aos direitos fundamentais para fazê-los valer contra atos de outros indivíduos ${ }^{44,45}$.

A eficácia direta, portanto, está comprometida com um projeto maximizador dos direitos fundamentais, para que os seus efeitos possam atingir as relações entre particulares independentemente de medida legislativa intermediadora.

No que diz respeito aos direitos sociais, a proteção à saúde do transexual diante da empresa de plano de saúde, conforme apontado no início da pesquisa, é um típico exemplo de problema que envolve a extensão de um direito social (saúde) em uma relação entre particulares (o paciente transexual e a empresa seguradora). Naquela situação, a juíza do caso fundamentou a necessidade de indenizar o tratamento negado diante da proteção da dignidade humana. Ainda que tenha apresentado como fundamento uma norma bastante geral, acredita-se que a decisão poderia ter sido baseada à luz da horizontalidade dos direitos sociais, já que o resultado foi o reconhecimento de que no contrato de prestação de saúde privada a empresa estava obrigada a prestar assistência independentemente da estipulação contratual em contrário. Tal negativa, ao violar um direito social à saúde em uma relação privada, é agravada quando se verifica que foi dada por meio do não respeito ao direito a

$\overline{{ }_{4} 4}$ SILVA, Virgílio Afonso da, op. cit., p. 90.

${ }^{45}$ No âmbito jurisprudencial, o Supremo Tribunal Federal manifestou-se favoravelmente à doutrina da eficácia direta nas relações entre particulares quando do julgamento do Recurso Extraordinário no 201.819/RJ (DJ 27/10/2006). Na ocasião, após analisar as diversas teorias que explicam o fenômeno da horizontalidade, o STF aplicou diretamente o direito fundamental à ampla defesa e ao contraditório a um sócio excluído de uma sociedade sem fins lucrativos. Antes mesmo dessa decisão, o Supremo Tribunal Federal já havia se manifestado a respeito da temática (RE 158.215-4 [DJ 30/04/96], RE 161.243-6 [DJ 29/10/96]), todavia, em que pese ter reconhecido direitos fundamentais no âmbito privado, não realizou qualquer referência à construção teórica que envolve o problema. 
um tratamento especializado aos transexuais. Ao dizer que o atendimento requerido com médico ginecologista não era possível aos indivíduos do sexo masculino, a empresa demonstrou o não respeito à identidade de gênero diferente do sexo biológico do paciente transexual.

\section{CONSIDERAÇÕES FINAIS}

O direito fundamental social à saúde trans, assim como os demais direitos sociais, apesar de se consubstanciarem em origem histórica distinta das liberdades públicas, exercem no âmbito do constitucionalismo brasileiro a mesma função, qual seja, a proteção da dignidade humana independentemente dos atores da relação jurídica.

A esfera privada-contratual não corresponde a um subsistema que se fundamenta em si mesmo, pois a centralidade do ordenamento jurídico advém da Constituição, a qual, permeada de direitos fundamentais concretizadores da dignidade humana, irradia um projeto de Estado e de Sociedade a ser construído em um ambiente de pluralismo democrático. Por essa razão, os demais subsistemas normativos devem ser relidos a partir de uma óptica constitucionalizante. No que toca aos direitos sociais, de maneira mais específica ao direito à saúde, é possível verificar sua potencialidade normativa para além das obrigações exclusivamente públicas. Não se postula uma substituição do Estado em desfavor da responsabilidade privada exclusiva, pelo contrário, horizontalizar os efeitos dos direitos fundamentais indica uma corresponsabilidade na efetivação desses direitos, uma concretização necessária principalmente diante de grupos vulneráveis como é o caso da população transexual.

A identidade de gênero é o ponto distintivo para a compreensão das peculiaridades que envolvem os transexuais. Quando se retoma a ação citada na introdução e julgada pela Justiça do Estado do Pará, nota-se que o atendimento à saúde negado à mulher trans decorreu da não diferenciação desse aspecto da sexualidade humana com o sexo biológico, pois a seguradora entendeu que um indivíduo do sexo masculino não poderia ter acesso à consulta com médico "exclusivo" para quem era do sexo feminino. Em razão disso, deixou de levar em consideração a identidade de gênero feminina da paciente que, mesmo com sexo biológico masculino, 
tem necessidade de atenção médica de ginecologista já que a saúde da transexual não se resume à cirurgia de redesignação sexual.

Em razão disso, acredita-se que a presente pesquisa logrou sucesso ao demonstrar que a tutela efetiva da saúde da população transexual estaria incompleta caso a teoria constitucional dependesse exclusivamente da concepção vertical em torno dos direitos fundamentais. Esse argumento, apesar de não ter estado presente na ação judicial do Estado do Pará, serve como instrumento teórico para o avanço de discussões futuras não restritas apenas ao direito social à saúde, mas também a todos os outros direitos sociais contemplados na Constituição Federal, a fim de se fortalecer a humanidade que existe entre todos, sem discriminação de identidade.

\section{REFERÊNCIA}

ARÁN, Márcia; ZAIDHAFT, Sérgio; MURTA, Daniela. Transexualidade: corpo, subjetividade e saúde coletiva. Psicologia e Sociedade, v. 20, n. 1, Porto Alegre, jan./abr. 2008.

BARRETTO, Vicente de Paulo. Reflexões sobre os direitos sociais. In: SARLET, Ingo Wolfgang (org.). Direitos fundamentais sociais: estudos de Direito Constitucional, Internacional e comparado. Rio de Janeiro: Renovar, 2003. p. 107-134.

BILBAO UBILLOS, Juan María. La eficacia de los derechos fundamentales frente a particulares: análisis de la jurisprudencia del Tribunal Constitucional. Madrid: Centro de Estudios Políticos y Constitucionales, 1997.

BRASIL. Supremo Tribunal Federal. Recurso Extraordinário 158.215-4. Rel. Min. Marco Aurélio. DJ 30/04/1996.

BRASIL. Supremo Tribunal Federal. Recurso Extraordinário 161.243-6. Rel. Min. Carlos Velloso. DJ 29/10/1996.

BRASIL. Supremo Tribunal Federal. Recurso Extraordinário 201.819. Rel. para o acórdão Min. Gilmar Mendes. DJ 27/10/2006.

BRASIL. Supremo Tribunal Federal. Ação Direta de Inconstitucionalidade 2.649. Rel. Min. Carmen Lúcia. DJ 08/05/2008. 
BRASIL. Supremo Tribunal Federal. Ação Direta de Inconstitucionalidade 939-7. Rel. Min. Sydney Sanches. DJ 18/03/1994.

CARVALHO, Osvaldo Ferreira de. Eficácia dos direitos fundamentais na esfera privada. Curitiba: Juruá, 2017.

CERQUEIRA, Elizabeth Kipman (org.). Sexualidade, gênero e desafios biológicos. São Caetano do Sul: Difusão, 2011.

CONSELHO FEDERAL DE MEDICINA. Resolução CFM no 1.955/2010. Disponível em: http://www.portalmedico.org.br/resolucoes/CFM/2010/1955_2010.htm. Acesso em: 14 mar. 2014.

CRUZ, Álvaro Ricardo de Souza. Um Olhar Crítico-Deliberativo sobre os Direitos Sociais no Estado Democrático de Direito. In: SOUZA NETO, Cláudio Pereira de; SARMENTO, Daniel. Direitos Sociais: Fundamentos, Judicialização e Direitos Sociais em Espécie. Rio de Janeiro: Lumen Juris, 2010.

DANIELLI, Ronei. A judicialização da saúde no Brasil: do viés individualista ao patamar de bem coletivo. Belo Horizonte: Fórum, 2017.

ESTRADA, Alexei Julio. La eficacia de los derechos fundamentales entre particulares. Bogotá: Universidad Externado de Colombia, 2000.

GARCÍA TORRES, Jesús; JIMENÉZ-BLANCO, Antonio. Derechos fundamentales y relaciones entre particulares: La Drittwirkung en la jurisprudencia del Tribunal Constitucional. Madrid: Editorial Civitas, 1986.

INSTITUTO ETHOS DE EMPRESAS E RESPONSABILIDADE SOCIAL. Perfil Social, Racial e de Gênero das 500 maiores empresas do Brasil e suas ações afirmativas. São Paulo, 2010.

LIMA, Ricardo Seibel de Freitas. Direito à saúde e critérios de aplicação. In: SARLET, Ingo Wolfgang; TIMM, Luciano Benetti (org.). Direitos fundamentais: orçamento e reserva do possível. Porto Alegre: Livraria do Advogado, 2008. p. 265-283.

MARTÍNEZ, Gregorio Peces-Barba. Derechos sociales y positivismo jurídico (Escritos de Filosofía Jurídica y Política): Instituto de Derechos Humanos Bartolomé de las Casas. Madrid: Dykinson, 1999. 
NEUNER, Jörg. Os direitos humanos sociais. In: SARLET, Ingo Wolfgang (coord.). Jurisdição e Direitos Fundamentais: anuário 2004/2005. Escola Superior da Magistratura do Rio Grande do Sul - AJURIS. Porto Alegre: Escola Superior da Magistratura: Livraria do Advogado, 2006.

NOVAIS, Jorge Reis. Direitos fundamentais: trunfos contra a maioria. Coimbra: Coimbra, 2006.

NUNES JUNIOR, Vidal Serrano. A Cidadania Social na Constituição de 1988: Estratégias de Positivação e Exigibilidade Judicial dos Direitos Sociais. São Paulo: Verbatim, 2009.

PEREIRA, Jane Reis Gonçalves. Apontamentos sobre a Aplicação das Normas de Direito Fundamental nas Relações Jurídicas entre Particulares. In: BARROSO, Luis Roberto (org.). A nova interpretação constitucional: ponderação, direitos fundamentais e relações privadas. Rio de Janeiro: Renovar, 2006.

PERES, Ana Paula Ariston Bario. Transexualismo: o direito a uma nova identidade sexual. São Paulo: Renovar, 2001.

PINTO, Paulo Mota. A influência dos direitos fundamentais sobre o direito privado português. In: MONTEIRO, António Pinto; NEUNER, Jörg; SARLET, Ingo Wolfgang (org.). Direitos fundamentais e direito privado: uma perspectiva de direito comparado. Coimbra: Almedina, 2007. p. 145-163.

PINTO, Paulo Mota. Autonomia privada e discriminação: algumas notas. In: SARLET, Ingo Wolfgang (org.). Constituição, direitos fundamentais e direito privado. 3. ed. rev. e ampl. Porto Alegre: Livraria do Advogado, 2010. p. 311-344.

PRINCÍPIO DE YOGYAKARTA. Disponível em: http://www.clam.org.br/pdf/principios_de_yogyakarta.pdf. Acesso em: 13 mar. 2014.

PULIDO, Carlos Bernal. Fundamento, Conceito e Estrutura dos Direitos Sociais: Uma Crítica a "Existem direitos sociais?" de Fernando Atria. In: SOUZA NETO, Cláudio Pereira de; SARMENTO, Daniel. Direitos Sociais: Fundamentos, Judicialização e Direitos Sociais em Espécie. Rio de Janeiro: Lumen Juris, 2010.

SARLET, Ingo Wolfgang. Direitos fundamentais sociais, "mínimo existencial" e direito privado: breves notas sobre alguns aspectos da possível eficácia dos direitos so- 
ciais nas relações entre particulares. In: SARMENTO, Daniel; GALDINO, Flávio (org.). Direitos fundamentais: estudos em homenagem ao professor Ricardo Lobo Torres. Rio de Janeiro: Renovar, 2006.

SARMENTO, Daniel. Direitos Fundamentais e Relações Privadas. 2. ed. Rio de Janeiro: Lumen Juris, 2006a.

SILVA, Virgílio Afonso da. A Constitucionalização do Direito: os direitos fundamentais nas relações entre particulares. São Paulo: Malheiros, 2005.

SILVA, Virgílio Afonso da. O judiciário e as políticas públicas: entre transformação social e obstáculo à realização dos direitos sociais. In: SOUZA NETO, Cláudio Pereira de; SARMENTO, Daniel (coord.). Direitos sociais: fundamentos, judicialização e direitos sociais em espécie. Rio de Janeiro: Lumen Juris, 2008. p. 587-599.

SNAZIAWSKI, Elimar. Limites e Possibilidade do direito de redesignação do estado sexual. São Paulo: Revista dos Tribunais, 1999.

STEINMETZ, Wilson. A vinculação dos particulares a direitos fundamentais. São Paulo: Malheiros, 2004.

TEPEDINO, Gustavo. A tutela da personalidade no ordenamento civil-constitucional brasileiro. In: TEPEDINO, Gustavo. Temas de direito civil. 3. ed. rev. e atual. Rio de Janeiro: Renovar, 2004. v. 1. p. 23-58.

VIEIRA, Tereza Rodrigues. O direito à mudança de sexo do transexual. Revista Jurídica Consulex, v. VIII, n. 181, jul. 2004.

VIEIRA DE ANDRADE, José Carlos. Os direitos, liberdades e garantias no âmbito das relações entre particulares. In: SARLET, Ingo Wolfgang (org.). Constituiçãa, Direitos Fundamentais e Direito Privado. 2. ed. Porto Alegre: Livraria do Advogado, 2006.

ZAMBRANO, Elizabeth. Parentalidade "impensáveis": pais/mães homossexuais, travestis e transexuais. Horizontes Antropológicos, Porto Alegre, v. 12, n. 26, jul./ dez. 2006. 